\title{
A Structural Simulation System, Part 2: Data Processing Center
}

\author{
Duan Jin ${ }^{1, a}$, Chen Xiao-ming ${ }^{1}$, Li Yun-gui ${ }^{1}$ \\ ${ }^{1}$ China State Construction Technical Center, Beijing, 101300, PR China \\ a duanjin78@126.com
}

Key words: finite element meshing, restraint management, damage assessment

Abstract: In this paper, the data processing center of the structural simulation system, an integrated simulation system for building structures, is presented. It includes two parts, i.e. the transformation from structural model to FE model and the result assessment. The former one includes the following contents such as finite element meshing, member's cross-section handling, restraint and connection management, shear wall's edge member modeling, etc. The latter one includes the following contents such as result assessment according to the civil codes, the damage assessment standard for structural members, the automatic generation of computation result report, etc.

\section{Introduction}

To satisfy the building engineering requirements for high performance simulation, an integrated simulation system for building structures, or ISSS for short, has been presented in the part one of this paper. It is a coalition of the traditional design software and general finite element analysis (FEA) software. Based on this system, the designed models, obtained by traditional design software, such as Pkpm, Yjk etc., could be automatically transformed to corresponding FE models ${ }^{[1-4]}$ and imported into commercial FEA software, such as Abaqus, Ansys etc., to finish the complex FE analysis.

In this paper, the data processing center of the structural simulation system, mentioned above, is presented. It includes two parts, i.e. the transformation from structural model to FE model and the result assessment. The former one includes the following contents such as finite element meshing, member's cross-section handling, restraint and connection management, shear wall's edge member modeling, etc. The latter one includes the following contents such as result assessment according to the civil codes, the damage assessment standard for structural members, the automatic generation of computation result report, etc.

\section{Transformation from structural model to FE model}

Transformation from structural model to FE model is the most important part of the structural simulation system. This transformation is finished automatically and includes the following contents: finite element meshing, member's cross-section handling, restrain and connection management, shear wall's edge member modeling.

\section{Finite element meshing}

Based on the paving meshing method ${ }^{[5]}$ and associated with mapping method ${ }^{[6]}$ and geometry decomposition method ${ }^{[7]}$, a new meshing scheme for building structures is developed and applied in the structural simulation system. This meshing scheme is very suitable for shear wall meshing, for it has the advantages of both the generality of arbitrary meshing and the efficiency of mapping meshing. Figure 1 gives some meshing examples of this scheme and its core idea could be stated as 
following: first, set the boundary nodes for the original building structural model, guaranteeing the node consistency of contiguous components, such as beams, columns, braces, shear walls, slabs, etc.; second, mesh the components with its boundary nodes. For the beams, columns and braces, one-dimensional meshing method is used; for the slabs, the paving method is used; while for shear walls, different meshing method is adopted considering that the shear wall is flat wall or curved wall. For the flat wall, mapping method or paving method is adopted according to the geometric features of the wall. For the curved wall, first transform the curved surface to the flat parametric surface, and then mesh the flat parametric surface just the same as flat wall, and finally transform the flat parametric surface to the original curved surface with the mesh transformed automatically. Generally speaking, the above meshing scheme has the following characteristics:

Geometry arbitrary: suitable for any complex building structures theoretically;

Boundary nodes consistency: the boundary nodes of contiguous components are strictly consistent and this characteristic is very suitable for finite element analysis;

Boundary elements priority: the meshing quality near the geometry boundary would be guaranteed preferentially, because relative the interior elements, the boundary elements have more dramatic effection for the finite element analysis;

Meshing homogeneity: the elements would be relatively homogenous and some transition elements would be inserted when the adjacent elements size changes suddenly and remarkably; Geometry orientation independence: the meshing results depend on the geometric topology of the structural model, independent with the coordinate system.

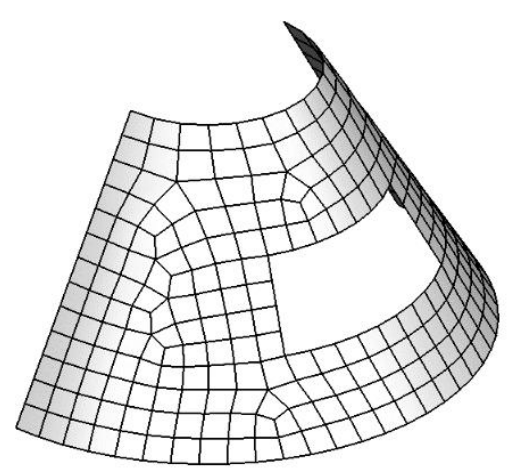

(a) mesh of curved surface

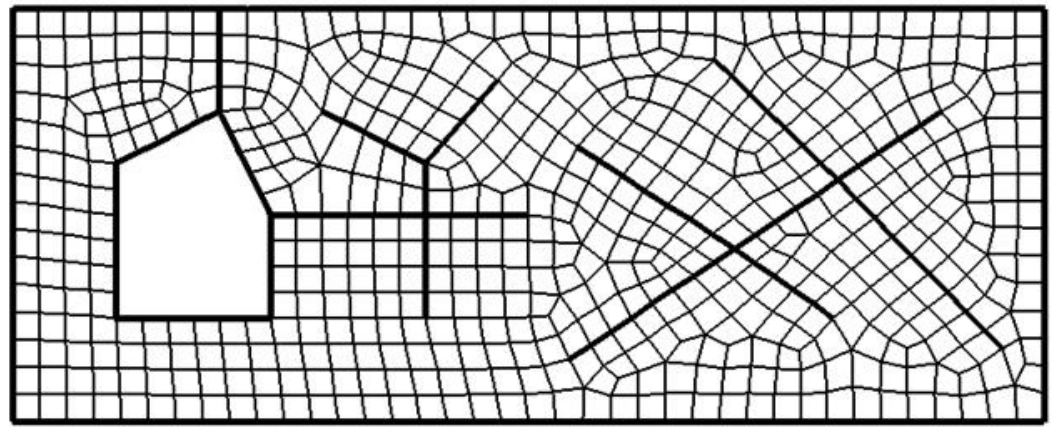

(b) mesh with line constrains

Figure 1 Mesh generation of the integrated simulation system

\section{Member's Cross-section handling}

The composite cross-section, which is widely used in the commercial FEA software, such as ANSYS, is adopted to reconfigure the component's cross-section in the structural simulation system. Figure 2 gives some illustration of the composite cross-section which can be explained detailedly as following: (1) cross-section of steel reinforced concrete component is decomposed into concrete cross-section and steel cross-section, and the position and amount of the steel cross-section are not confined. And the above characteristics is very suitable for the giant columns widely used in the super high-rise building; (2) the sections of shear wall and plate are also described as composite cross-section, with the purpose of modeling the special section of steel reinforced concrete shear wall, box wall, composite slabs, etc.; (3) just the same as the commercial FEA software, the offset of component's cross-section is also described as composite cross-section and the detailed information of offset is stored in the information of cross-section. 

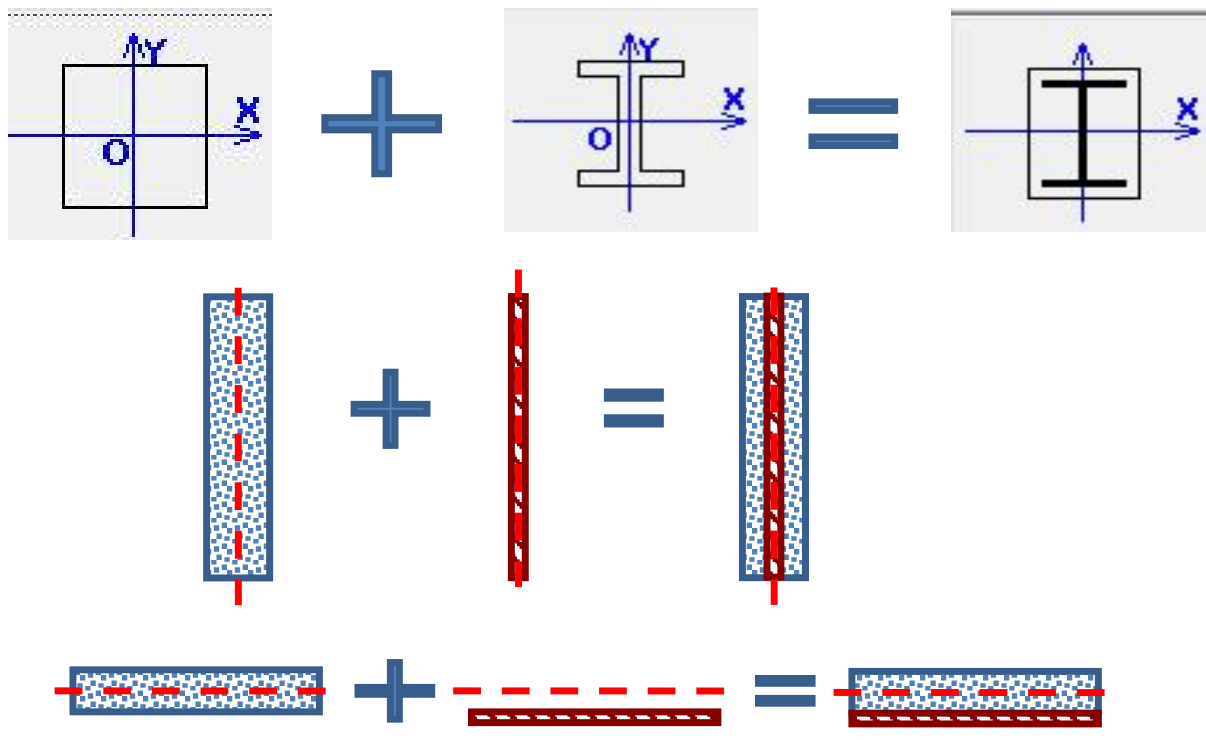

Figure 2 Illustration of the compound component's intersection

\section{Restraint and connection management}

The constraint and connection in the structural simulation system mainly include the following parts: support, hinge node, offset of component, rigid bar, rigid slab, wall-beam connection, etc. The supports and hinge nodes are modeled as constraint equations. The offsets are modeled either as composite cross-sections, which one would not increase additional nodes but increase additional cross-section, or as constraint equations, which would increase additional nodes.

The rigid bars and rigid slabs in the building structure would perhaps interconnect and result in complicated rigid region, so the modeling of rigid bars and rigid slabs use the same method, explained as following:

(1) search every story and determine all of the block rigid region, which is the interconnected rigid bars and rigid slabs;

(2) configure the master and slave nodes according to the block rigid region and preferentially select an intersection node of the rigid bar and rigid slab as the master node;

(3) set the constraint equations according to the configuration of master and slave noes, and only constrain the in-plane DOFs for the nodes of rigid slab.
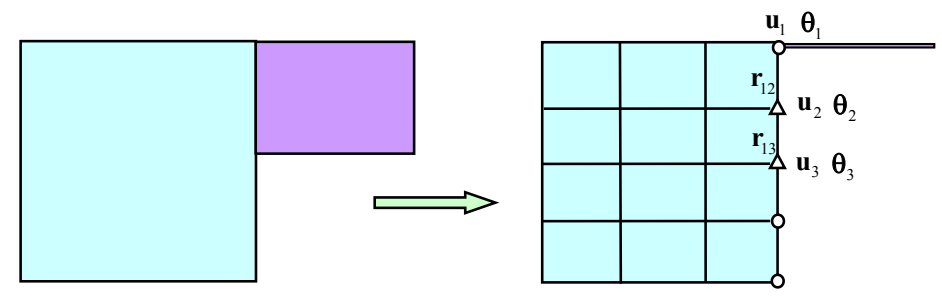

Figure 3 Illustration of the wall-beam conneciton

In the structural geometric model, the connection region between beam and wall is an area with the height equaling the beam's height. When the geometric model is discreted into finite elemental model, the connection region is simplified to a point with zero height, see Figure 3 . This simplification does not meet the real occation and needs to be modified in the subsequent finite element analysis. This is the problem of wall-beam connection and the structural simulation system 
presents two method, i.e. constraint equation and penalty element. The former method would introduce constraint equations based on the original nodes. It is a kind of rigid connection. The later method would introduce additional element. It is a kind of half-rigid connection.

Besides the above constraint and connection, there are some other special connection in buidling structure, such as one column supporting two columns, one column supporting two beams, column supporting wall, one beam supporting two pieces of shear wall, etc. All of the above mentioned special connection would be modeled as constraint equations in the structural simulation system.

\section{Shear wall's edge member modeling}

The edge member of shear wall is illustrated in Figure4. Its reinforcement, i.e. longitudinal bar and stirrup, is clearly different from the other reinforcement of the wall. It is obviously that the reinforcement of edge member is more like the reinforcement of concrete column. Therefor the edge members need some additional treatment other than that of shear walls. For the structural simulation system presented in this paper, a simplified treatment is adopted that the restriction between the stirrup and the concrete is ignored and the effects of the longitudinal bars are considered by additional rod element with steel material.

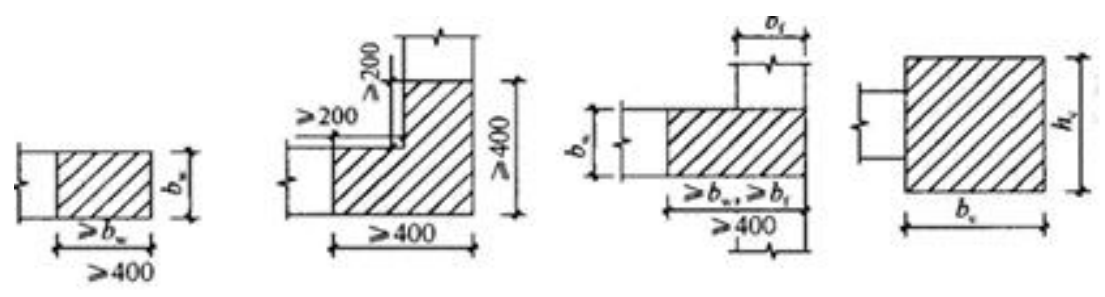

Figure 4 Illustration of shear wall's edge members ${ }^{[8]}$

\section{Result assessment}

The structural simulation system would automatically read out the computation results from the commercial FEA software, and estimate the damaged condition, and finally generate the computation result report.

\section{Result assessment according to the civil codes}

Computation result assessment could be divided into two types, i.e. 1) based on the structural members, see Table 1 for details, and 2) based on the structural stories, see Table 2 for details. 
Table 1 Result assessment based on structural members

\begin{tabular}{ll}
\hline Assessment & Explanation \\
\hline $\begin{array}{l}\text { Time history of displacement angle } \\
\text { Time history of internal force }\end{array}$ & $\begin{array}{l}\text { Only consider the vertical components, i.e. columns, wall columns, etc. } \\
\text { Consider the axial force, shear force and bending moments for beams, columns, and braces; } \\
\text { while only consider the axial force and shear force for wall columns and wall beams. }\end{array}$ \\
$\begin{array}{l}\text { Time history of nominal axial } \\
\text { compression ratio }\end{array}$ & $\begin{array}{l}\text { The axial force is the response under the combined action of dead load and seismic load, } \\
\text { while the concrete strength is the standard value and consider the degeneration resulted from }\end{array}$ \\
Time history of damage and & $\begin{array}{l}\text { Consider the cross section at the ends of beams, columns, braces, wall beams, wall columns. } \\
\text { stiffness degeneration } \\
\text { Time history of plastic strain }\end{array}$ \\
Hysteretic curve of shear force and \\
shear displacement \\
M- $\theta$ curve
\end{tabular}

Table 2 Result assessment based on structural stories

\begin{tabular}{ll}
\hline Assessment & Explanation \\
\hline $\begin{array}{l}\text { Time history and envelope of } \\
\text { displacement angle }\end{array}$ & $\begin{array}{l}\text { Take the maximum displacement angle of structural members in the story as the story } \\
\text { displacement angle. }\end{array}$ \\
$\begin{array}{l}\text { Time history and envelope of damage } \\
\text { displacement angle }\end{array}$ & $\begin{array}{l}\text { The damage displacement angle is obtained by the following way that use the average } \\
\text { displacement angle of structural members in the story to subtract the displacement } \\
\text { angle resulted from the rigid rotation of the lower floor. }\end{array}$ \\
$\begin{array}{l}\text { Time history of the maximum and } \\
\text { average lateral displacement }\end{array}$ & $\begin{array}{l}\text { To estimate the torsional effect of story. } \\
\text { Time history and envelope of shear } \\
\text { force }\end{array}$ \\
$\begin{array}{l}\text { Time history of shear force and } \\
\text { vertical reaction at basement }\end{array}$ & $\begin{array}{l}\text { Accumulate the reaction at support. } \\
\text { Time history of upsetting moment } \\
\text { Hysteretic curve of story shear force } \\
\text { and shear displacement }\end{array}$ \\
$\begin{array}{l}\text { Include the total upsetting moment and frame's upsetting moment. } \\
\text { The story shear force is the average value of the vertical components at the same story } \\
\text { and the story shear displacement is referred to the relative story displacements. }\end{array}$ \\
$\begin{array}{l}\text { Estimate the damaged structural components, including the quantity, member number, } \\
\text { compression damage and plastic strain, etc., according to the damage assessment } \\
\text { standard, see Table } 3 .\end{array}$ \\
\hline
\end{tabular}

\section{Damage assessment standard for structural members}

The damage assessment standard for structural members, shown in Table 3, is adopted by the structural simulation system by default. While the user defined standard is also allowed by the system. 
Table 3 Damage assessment standard for structural members

\begin{tabular}{cccccc}
\hline Material type & \multicolumn{5}{c}{ Damage assessment } \\
\cline { 2 - 6 } & None & Mild & Slight & Moderate & Fantasy \\
Plastic strain of steel & - & $0 \sim 0.004$ & $0.004 \sim 0.008$ & $0.008 \sim 0.012$ & $>0.012$ \\
Compression damage of & - & - & $0 \sim 0.1$ & $0.1 \sim 0.3$ & $>0.3$ \\
$\quad \begin{array}{c}\text { concrete } \\
\text { C. }\end{array}$ & & & & & \\
\hline
\end{tabular}

\section{Generation of computation result report}

The structural simulation system would automatically generate the computation result report and its contents include the following parts: the project profile, the structural design model and computational FE model, the computational option setting and analysis parameter setting, the computation result assessment and damaged condition estimation, the conclusion and advices, etc.

\section{Summary}

The data processing center of the structural simulation system, an integrated simulation system for building structures, is presented in this paper. It includes two parts, i.e. the transformation from structural model to FE model and the result assessment. The former one includes the following contents such as finite element meshing, member's cross-section handling, restraint and connection management, shear wall's edge member modeling, etc. The latter one includes the following contents such as result assessment according to the civil codes, the damage assessment standard for structural members, the automatic generation of computation result report, etc.

\section{Reference}

[1] Li Y.G., Duan J. \& Chen X.M. Simulation Analysis and Engineering Examples for Building Structures [M]. Beijing: China Building Industry Press, 2015. (in Chinese)

[2] Duan J., Chen X.M. \& Li Y.G. A Quadrilateral Meshing Method for Shear-Wall Structures [J]. Applied Mechanics and Materials. 2014, 638-640: 9-14.

[3] Duan J., Chen X.M., Qi H. \& Li Y.G. Boundary-Constraint Meshing Based on Paving Method [J]. Applied Mechanics and Materials. 2014, 627: 262-267.

[4] Duan J., Chen X.M., Qi H. \& Li Y.G. An Automatic FE Model Generation System Used for ISSS [C]. Proceedings of Civil Engineering and Urban Planning III. Landon, UK: Taylor \& Francis Group. 2014: 29-32.

[5] Blacker T.D. \& Stephenson M.B. Paving: A New Approach to Automated Quadrilateral Mesh Generation, International Journal for Numerical Methods in Engineering. 1991, Vol 32: $811-847$

[6] Cook W.A. \& Oakes W.R. Mapping Methods for Generating Three-Dimensional Meshes, Computers in Mechanical Engineering, 1982, pp. 67-72

[7] Baehmann P.L., Wittchen S.L., Shephard M.S., Grice K.R. \& Yerry M.A.. Robust Geometricallybased, Automatic Two-Dimensional Mesh Generation, International Journal for Numerical Methods in Engineering. 1987, Vol.24: 1043-1078

[8] GB-50010-2010. Code for Design of Concrete Structures. Beijing: China Building Industry Press (2011). (in Chinese) 